\title{
LO QUE EL RÍO SE LLEVÓ, BAJO EL SILENCIO DE LAS MONTAÑAS
}

\author{
Doris Beltrán Ramírez \\ Profesional en Gestión Empresarial \\ Secretaria Vicerrectoría Académica \\ Universidad Santo Tomás \\ secacad@mail.ustabuca.edu.co
}

\author{
Diana Marcela Rueda Duarte \\ Secretaria Centro de Gestión de Calidad \\ Universidad Santo Tomás \\ dmarcerd@gmail.com
}

Recuerdo que en los años 80 la Guerrilla de las FARC, Ilamadas Fuerzas Armadas Revolucionarias de Colombia y el ELN -Ejército de Liberación Nacional-, se enfrentaban por ganar territorios del Magdalena Medio, en el departamento de Santander Colombia, específicamente en San Vicente y El Carmen de Chucurí, denso territorio conocido como "zona roja", en donde las carreteras eran caminos trazados por las herraduras de las mulas y sus arrieros que temerosamente sacaban sus cultivos de plátano, yuca y aguacate. Siempre esperaban la mejor oferta para venderlos o, en el peor de los casos, como solía suceder, terminaban en las ollas y almuerzos de las llamadas marchas patrióticas.

\section{Presencia inesperada}

Allí los campesinos a principio de enero empezaban a planear sus cultivos, de los cuales se esperaba el sustento de sus vidas que transcurría en ires y venires de extraños que se asomaban en manada como el humo que penetraba por entre el medio de las tablas de las cocinas campesinas, ese que no se puede rechazar o hacer nada para alejarlo, a sabiendas de que no se tiene otra opción aparte de la leña y el fogón de barro para preparar los alimentos. Así era, no había razón, ni motivo para demostrar la fuerza interior que repelía su presencia, ya se sabía que el mejor café de la mañana era para ellos, la gallina de los huevos grandes y azules podría ser para ellos, la vaca y el cerdo no tenían ningún valor cuando su presencia intimidante se asomaba, pues fácilmente los tomaban de un lazo y se los llevaban cuesta abajo.

\section{Sin desayuno para la escuela}

Una mañana, mi señora madre apenas se levantaba y como de costumbre prendió el fogón y puso hacer el café que era su primer oficio. Entre tanto, yo me cepillaba los dientes en la pila del agua para alistarme e irme a la escuela. Asomaron por detrás del patio de la casa como animales carnívoros al asecho de su presa, camuflados entre el verde del jardín y sus botas largas pantaneras que sonaban como cuando bajaban de la montaña las mulas y el ganado sedientos en busca de la quebrada. No sabíamos si traían hambre o sed, lo único que puedo dar fe, es que a mi mamá, en vez de prepararnos el desayuno, le tocó poner la olla más grande que tenía y restar de sus gallinas dos de las más gordas, pues así se lo ordenaron. Ese día, no hubo desayuno, tampoco media mañana, me tuve que ir a la escuela ubicada a unos 200 metros de mi casa, sin mediar palabra y sin preguntar nada. Las profesoras Lilia y Melba las únicas que dictaban clases en este caserío, cerraban las puertas de los dos salones de la escuela $y$, temerosas como esperando que sucediera algo, se asomaban cada cinco minutos por la ventana para observar disimuladamente sus movimientos; para nosotros era intimidante, pero a la vez normal, pues no entendíamos a los 10 años, el por qué de tan recurrentes visitas y más aún, teniendo en cuenta que el saludo venía acompañado de la palabra "compañero"y "compañera" y las muestras de afecto y cercanía con los niños varones que no se hacían esperar, tanto que algunos prefirieron abandonar su escuela para irse a conocer el mundo mágico 
que les pintaban, ese que los desaparecía y sus familias no volvían a saber de ellos, así como le sucedió a un hijo de don Benito Ardila.

\section{Respuestas inconclusas}

Al preguntarle a mi mamá, el por qué se los llevaban, ella me dio dos razones: una porque los jóvenes entre 15 y 16 años se cansaban de trabajar al lado de sus padres como jornaleros y querían vivir otra historia y, otra, por toda la estrategia que como vendedores acerbos de su causa éstos ofrecían maravillas a las mentes ignorantes ya fueran jóvenes o adultas y lo peor, suficientemente incapaces de elegir el camino correcto.

Ahí traté de comprender, por qué al papá de mi mejor amiga se lo llevaron y mientras ella dormía su presencia se esfumó, sin respuesta, sin amor, sin ni siquiera dolerle su hija, así se marchó. "Mi papá se enamoró de las armas", "mi papá me abandonó", eso me dijo cuando yo le preguntaba por él. Después de visitar varios campamentos y de compartir ratos robados con él en medio de la selva, zancudos, armas y personajes vestidos de verde pasto, pasaron dos años y medio, hasta que la noticia nefasta llegó. El Comandante de las Farc, alias Marcos falleció en un encuentro con la guerrilla en territorios de Puente Nacional, Santander.

Sigilosos, pero con autoridad, así muchas veces los vi llegar, una que otra familia era partidaria de sus visitas, hasta parecían de su más cercana intimidad, mientras que la gran mayoría vivían de la zozobra, pues se iba la guerrilla y a los dos días llegaba el ejército preguntando que si todo estaba normal y la respuesta siempre era la misma: "por aquí nadie ha venido", "todo está bien". Se iban, sin encontrar respuestas, ni razones a la información que tenían y a las denuncias de desaparecidos que 15 días después se hallaban boca abajo, sin ropa, descompuestos y atrapados entre las ramas que arrasaba la corriente del río.








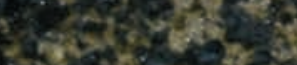

Tis.

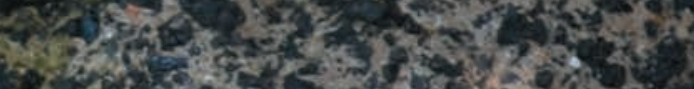

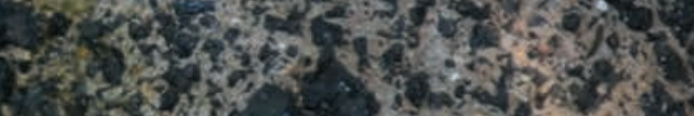
3.

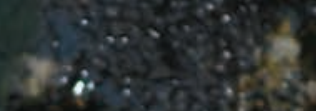

a.:<smiles>c1ccc2ccccc2c1</smiles>

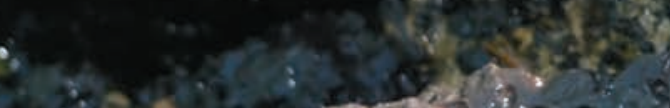

ins.

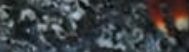
$\sin ^{2}$ trand on 3.

(t)


Y.

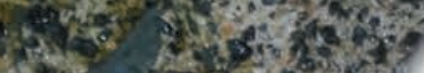

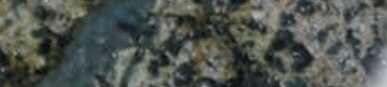

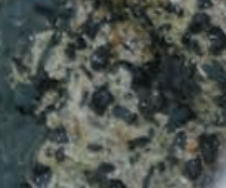

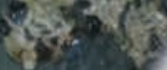

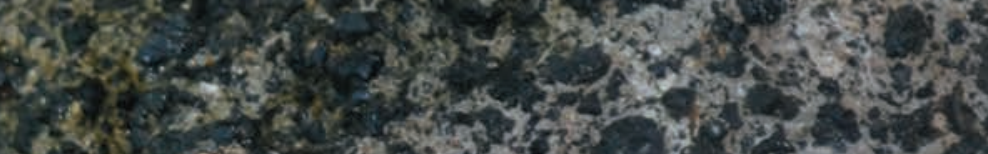



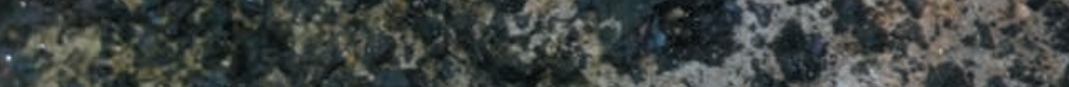

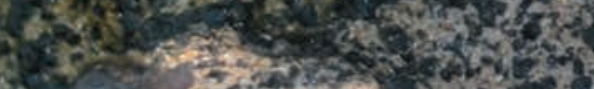


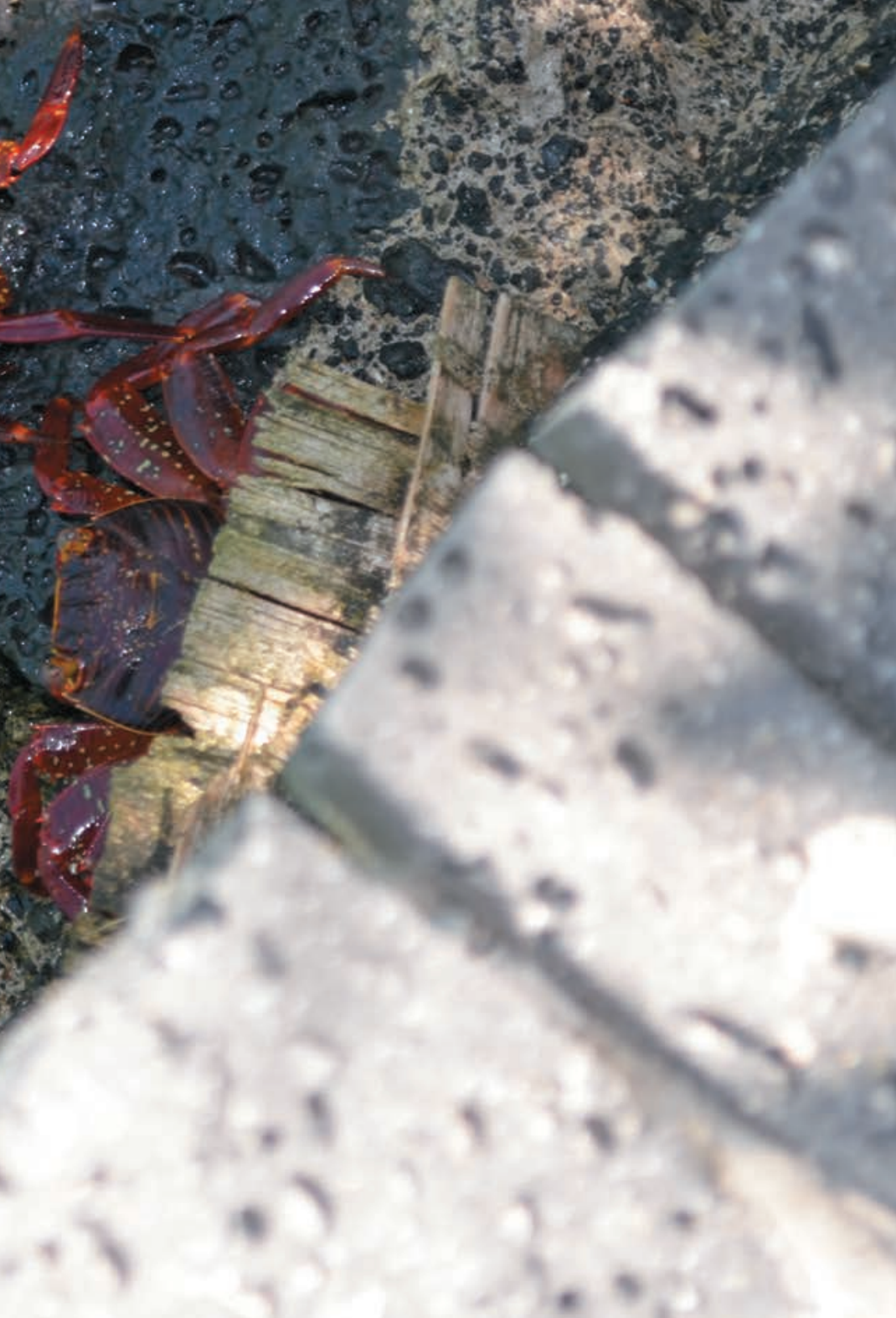
tingents



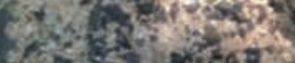

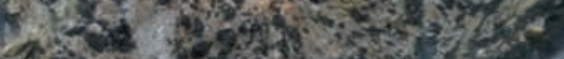

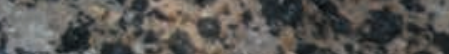

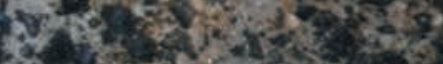
$\frac{425}{3 y^{2}}$ 


\section{Un paseo sin fortuna}

La situación cada vez era más aguda, mientras unos querían seguir ocultando lo que sucedía, otros querían contarlo todo, así les costara la vida, como le sucedió a Pedro Toscano la flor del trabajo, le llamaban así porque de los cinco días de la semana, dos viajaba a Barrancabermeja, lo que lo hacía sospechoso de llamarse informante, así lo catalogaron y así lo sepultaron. Todos lo vieron pasar por el caserío con cuatro hombres detrás de él, como si fuera una consigna para aquellos que decidieran ir en contra de sus leyes, iba agachado, él que siempre saludaba "adiós doña Ceci", ese día no levantó cabeza, tal vez buscando que el camino se abriera y se lo tragara antes de morir acribillado por la espalda con ráfagas de fusil. Así lo encontró su papá, el señor Alirio Toscano, amarrado de pies y manos y con los ojos vendados en medio de un matorral.

La gente atemorizada y con deseos de huir, no se atrevía a hacerlo, ya que las amenazas en contra de sus familias caían en cascada y ni modo, hay que esperar a que todo se calme, eso decían. Entre tanto, Lilia la profesora de quinto primaria, decidió empacar su maleta e irse para Barrancabermeja en donde residía, dejándole los dos cursos de cuarto y quinto a la profesora Melba, así terminamos el año escolar, con una profesora que atendía medianamente a cinco grupos y que muchas veces, repetía el mismo tema para todos los estudiantes.

\section{Negros nubarrones rodeados de aves rapiñas}

Los días transcurrían entre el temor y los oficios cotidianos del campo, las jornadas de trabajo podrían ser de media jornada, teniendo en cuenta que campesinos verdes del susto y sin oxígeno llegaban a sus hogares escondiéndose de las ráfagas de fusil, granadas y bombas que como baldados de agua caían del cielo aventados sin piedad por vida alguna. Días después, inmensos nubarrones de aves negras que revoloteaban en lo más alto de la montaña eran el medio informativo que anunciaban guerrilleros y animales de toda especie en descomposición.

\section{Cuando el río suena...}

Nadie los reconocía, nadie los preguntaba. Sólo se murmuraba de campesinos rebeldes, opositores de la guerrilla, jóvenes amigas de militares y personajes que de alguna u otra manera eran "enemigos de la causa", así rodaban río abajo como buscando su hogar, un doliente, un escape que de hecho ni el mismo Dios a quien clamaban por sus vidas les ayudaría a encontrar. 